\title{
Predicted impacts of government policies and actions on the SARS-CoV-2 disease in the northwestern Himalayan region, India
}

\author{
Shiekh Marifatul Haq ${ }^{1} \cdot$ Umer Yaqoob $^{2} \cdot$ Musheerul Hassan $^{2} \cdot$ Rafaela José da Silva $^{3}$ (D) Eduardo Soares Calixto ${ }^{4}$ (I)
}

Received: 24 June 2020 / Accepted: 3 April 2021 / Published online: 16 April 2021

(C) The Author(s), under exclusive licence to Springer-Verlag GmbH Germany, part of Springer Nature 2021

\begin{abstract}
Aim The outbreak of the new coronavirus pandemic (SARS-CoV-2) was initiated in December 2019, and within a couple of months it became a global health emergency. Given the importance to assess the evolution and transmissibility of SARS-CoV-2 and to forecast the next scenario of the pandemic, mainly in countries with limited healthcare systems, we estimated the reproductive number (R0) of SARS-CoV-2 in Jammu and Kashmir (J\&K), India, and a possible scenario for this pandemic in the region.

Subject and methods We estimated the reproductive number (R0) of SARS-CoV-2 in its first outbreak stage in the northwestern region of Himalaya, India, and we also predicted new daily cases for the next 90 days using different $\mathrm{R} 0$, testing a plausible end of the SARS-CoV-2 outbreak.

Results Our results showed a considerable increase in the number of cases, but with a tendency to asymptote. Anantnag, Bandipora, Baramulla, Shopian, and Srinagar districts showed more than 100 cases and Kulgam and Kathua districts showed strong growth of the number of cases from the beginning of May, without a tendency to normalization. The estimated R0 for the $\mathrm{J} \& \mathrm{~K}$ region was 1.041 ; but by decreasing the RO by 10,25 , and $50 \%$, we observed a great decrease in the daily number of new cases, especially by decreasing by $50 \%$.

Conclusion In this study, we indicate positive effects of the preventive measures, such as lockdown and social distancing, taken in the J\&K region, showing a stabilization of the growth curves of new cases of SARS-CoV-2, which tends to a strong decrease over time as the $\mathrm{R} 0$ decreases.
\end{abstract}

Keywords Covid-19 $\cdot$ Coronavirus $\cdot 2019 n-C o V ~ \cdot$ Pandemic $\cdot$ Transmissibility $\cdot$ Infectious disease

Shiekh Marifatul Haq and Eduardo Soares Calixto contributed equally to this work.

Eduardo Soares Calixto

calixtos.edu@gmail.com

Shiekh Marifatul Haq

snaryan17@gmail.com

Umer Yaqoob

umerraj6668@gmail.com

Musheerul Hassan

musheer123ni@gmail.com

Rafaela José da Silva

rafaela_jsilva@hotmail.com
Department of Botany, University of Kashmir, Hazratbal, Srinagar, J\&K 190006, India

2 Department of Life Science, Pacific University, Udaipur 313003, India

3 Laboratory of Immunophysiology of Reproduction, Institute of Biomedical Science, Federal University of Uberlândia, Uberlândia 38408100, Brazil

4 Institute of Biology, University of São Paulo, Ribeirão Preto 14040900, Brazil 


\section{Introduction}

Currently, the whole world is dealing with one of the most severe epidemic viral diseases, first reported in Wuhan province, China, in December 2019. This disease was named by the world health organization (WHO) as coronavirus disease 19 (Covid-19), caused by a novel coronavirus, primarily named as 2019n-CoV, and later as Severe Acute Respiratory Syndrome Coronavirus-2 (SARS-CoV-2) (Gorbalenya et al. 2020). Phylogenetic studies have shown that SARS-CoV-2 is directly linked to two bat-related SARS-like coronaviruses bat-SL-CoVZXC21 (GenBank accession no. MG772934.1) and bat-SL-CoVZC45(GenBank accession no. MG772933.1) with approximately 88-89\% similarity (Jiang et al. 2020; Lu et al. 2020; Ren et al. 2020). Furthermore, it was also found that this new virus is associated with horseshoe bats (Rhinolophus genus), with approximately $98.7 \%$ sequence similarity to the $R d R p$ (RNA-dependent RNA polymerase) gene of $\mathrm{BtCoV} / 4991$ strain of bats (GenBank KP876546) and approximately $87.9 \%$ sequence with batSL-CoVZXC21 and bat-SL-CoVZC45 strains of bats (Chen et al. 2020a).

Evolutionary studies based on $\mathrm{S}$ and $\mathrm{N}$ genes and ORF1a/ $1 \mathrm{~b}$ have predicted that SARS-CoV-2 is a new strain of coronavirus independently transmitted from animals to humans (Chen et al. 2020a). On the basis of these investigations and the incidence of some species of bats and other animals in the seafood market in the Wuhan province of China, it was speculated that SARS-CoV-2 may have been transmitted from bats to humans (Zhou et al. 2020), presuming animal to human spread (Chen et al. 2020b). However, studies have also indicated human to human transmission through direct contact or droplet transmission (Huang et al. 2020).

This virus is tentatively presumed to have an average incubation period of 6.4 days and $\mathrm{R} 0$ (basic reproductive number) of 2.24-3.58 (Zhao et al. 2020). The clinical manifestations of the disease can vary from asymptomatic to severe cases, leading to an individual's death (Jin et al. 2020). Among the patients with SARS-CoV-2, fever was the most common symptom $(92.8 \%)$, but others can be included, such as cough, myalgia, headache, dyspnea, and diarrhea (Chen et al. 2020b). Rhinorrhea was also reported in approximately $4.0 \%$ of cases, pharyngalgia in $17.4 \%$, and sore throat in $5.1 \%$ of SARSCOV-2 cases whose clinical data was available (Chen et al. 2020b). Moreover, ground-glass opacity of lungs observed by computed tomography images of the lungs was the most common clinical symptom found in cases (Chung et al. 2020).

Although different medications have been used as treatment (Chen et al. 2020b; Huang et al. 2020; Wang et al. 2020), the scientific community has not been able to develop effective treatment for SARS-CoV-2. Then, several countries have taken measures of social isolation/distancing and total lockdown, as a way to decrease the transmission of the disease and avoid overcrowding in treatment centers (e.g., hospitals). As of May 12, 2020, the WHO reported more than 4.1 million confirmed cases of and 287,000 deaths from this deadly viral epidemic in more than 190 countries (https://www.who.int/ emergencies/diseases/novel-coronavirus-2019/situationreports). Specifically in India, WHO has reported more than 74,281 confirmed cases of SARS-CoV-2, and 2415 deaths as of May 12, 2020 (https://www.who.int/emergencies/diseases/ novel-coronavirus-2019/situation-reports).

It is extremely important to assess the evolution and transmissibility of SARS-CoV-2, and to forecast the next scenario of the pandemic. Assessing these factors, government agencies will be able to act more accurately, investing in preventive and treatment measures in the most affected regions, especially in developing countries such as India. Here we estimated the reproductive number (R0) of SARS-CoV-2 in its first outbreak stage in the North western region of Himalaya, India, and we also predicted new daily cases for the next 90 days using different $\mathrm{R} 0$, testing a plausible end of the SARS-CoV-2 outbreak. Using different $\mathrm{R} 0$ values enables us to predict how preventive measures (e.g., lockdown and social distancing) are important for decreasing SARS-CoV-2 transmissibility. This is the first study conducted in this region evaluating the current situation and proposing future outcomes of SARS $\mathrm{CoV}-2$, and it will have positive implications in planning current and future measures.

\section{Methodology}

\section{Studied region}

Our study focused on a region of India, Jammu and Kashmir (J\&K), located at the northern-most part of the country. It covers an area of $42,241 \mathrm{~km}^{2}$, which extends between $33.7782 \mathrm{~N}$ and 76.5762E (Fig. 1). The region is separated by the line of control from the Pakistan-administered territories of Azad Kashmir and Gilgit-Baltistan in the west and north, respectively. It lies on the north of the Indian states of Himachal Pradesh and Punjab and the west of Ladakh. The Himalayas divide the Kashmir valley from the Tibetan plateau while the PirPanjal range, which encloses the valley from the west to the south, separates it from the Great Plains of northern India. The Union Territory is divided into two bio-geographic provinces, Jammu and Kashmir, which differ in terms of climate, culture, and physiographics. As per the 2011 census, the population of Jammu and Kashmir is approximately 12.5 million.

\section{Data source}

We monitored and analyzed the cases of all districts (20) in Jammu and Kashmir (Fig. 1), India, namely Anantnag, 


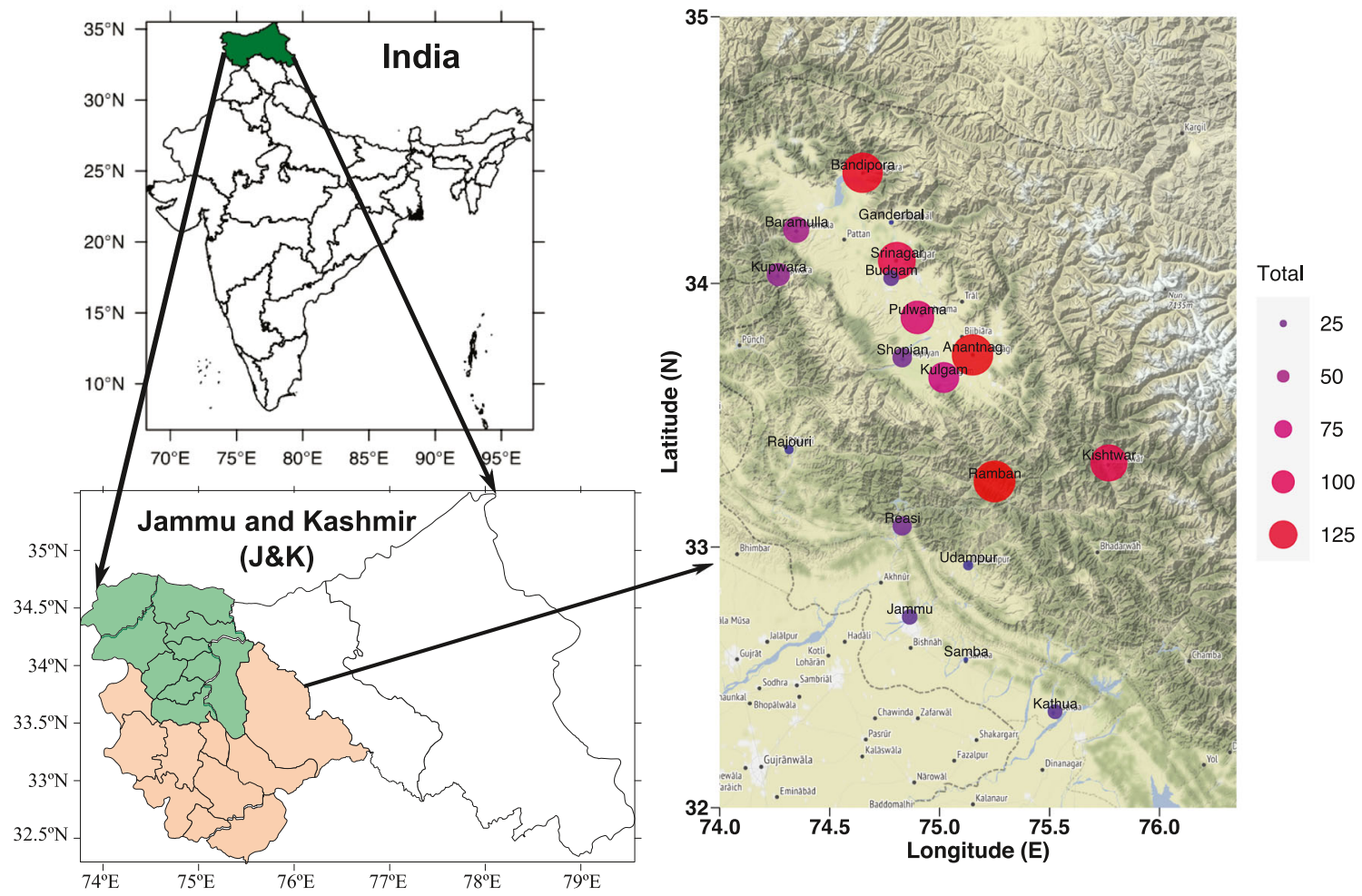

Fig. 1 Map of the study area showing the Jammu \& Kashmir region, India (left), and the 18 districts evaluated with proportional number of cases reported

Bandipora, Budgam, Baramulla, Doda, Ganderbal, Jammu, Kupwara, Kulgam, Kathua, Kishtwar, Poonch, Pulwama, Rajouri, Ramban, Reasi, Srinagar, Shopian, Samba, and Udampur. We gathered the data from various sources, such as official twitter handle of "Principal secretary planning \& information" of the government of J\&K (Mr. Rohit Kansal) (https:// twitter.com/kansalrohit69), Official twitter handle of Department of Information \& Public Relations of the government of J\&K (https://twitter.com/diprjk/status/), as well as other sources the "E" newspapers of J\&K which included Greater Kashmir (http://epaper.greaterkashmir.com/), and Rising Kashmir (http:// epaper.risingkashmir.com/). We also followed the website (https://covidkashmir.org/), which is the unique website in J\&K providing the updated information regarding SARS-CoV-2 patients. To verify our data, we cross-checked it with the information on the website of the ministry of health and family welfare government of J\&K (https://www.mohfw.gov.in/). We divided the cases based on active, recovered, and deaths. All these were monitored every day in every district of J\&K from the first reported case (March 9, 2020) until May 12, 2020 (two months).

\section{Analyses}

All plots and analyses were performed using R 4.0 .0 with 5\% probability. First, we used bar plots to visualize the current circumstances of SARS-CoV-2 in these districts, assessing the number of active cases, recovered, and deaths. In addition, we constructed accumulation curves to observe the trend of active cases and deaths in 18 districts of J\&K, and in the J\&K region as a whole. We used only 18 districts because Doda and Poonch did not present any reported cases. In these curves, we chose to transform and plot the data in $\log 2$ to facilitate visualization and comparison of the data among each district, and these with the total.

For other analyses, we used the serial interval and the R0 (reproductive number). Serial interval is the duration between symptom onset of the first and second case given a transmission chain; and R0 is the expected number of secondary cases that one primary case may generate in a susceptible population (Li et al. 2020; Zhang et al. 2020).

To assess the transmissibility of SARS-CoV-2 in the J\&K region, we estimated the R0 in the early stage of the SARSCoV-2 outbreak in the region using the package "early R" (Jombart et al. 2017). First, we obtained the serial interval, which is required to estimate $\mathrm{R} 0$, using the mean (7.5 days) and standard deviation (3.4 days) values from SARS-CoV-2 in Wuhan, China (Li et al. 2020). Then, we fit the serial interval value with gamma distribution and maximum-likelihood (ML) estimate of R0. We also used a bootstrap analysis (1000 randomizations) to obtain a sample of plausible $\mathrm{R} 0$ values and 
derive other statistics for this distribution (Jombart et al. 2017).

To predict plausible disease trajectories simulation and future daily incidence prediction, we used the package "projections" (Jombart and Nouvellet 2020). A model based on past incidence data, selection of plausible R0, and the distribution of the serial interval with Poisson distribution (determined by daily infectiousness) was fit to observe the simulation and prediction. Our observed R0 was equal to 1.041 (see results), and our randomized R0 was equal to 1.038; then we used $\mathrm{R} 0=1.041$ in our analysis for being relatively the same value of R0 provided by the null model. As our data has a range of 60 days, we predict future incidence for the next 90 days. We used a bootstrap resampling method with 1000 randomizations.

Finally, we decreased the R0 value by $10 \%(\mathrm{R} 0=0.9)$, $25 \%(\mathrm{R} 0=0.75)$, and $50 \%(\mathrm{R} 0=0.5)$ to predict plausible disease trajectories simulation and future daily incidence prediction in the next 90 days. This analysis will show us how the future daily incidence evolves with a decrease in expected number of secondary cases that one primary case may generate in a susceptible population. In other words, we are evaluating how social distancing and lockdown are important for the evolution of SARS-CoV-2 cases in the J\&K region.

\section{Results}

Our results showed that the total number of cases (active, recovered, and deaths) in these 18 districts in $\mathrm{J} \& \mathrm{~K}$ was 934 (Table 1). Of this total, 469 (50.2\%) are active, 455 (48.7\%) are recovered, and only 10 (1.1\%) died (Table 1, Fig. 2). The first case of SARS-CoV-2 was reported from the Jammu district on March 9, 2020, and the first death was reported from the Srinagar district on March 24, 2020. In general, as of March 22, there has been a considerable increase in the number of cases, but with a tendency to asymptote. Considering these 18 districts, it remains unclear if there is a decrease in the number of cases and deaths; however, our accumulation curves show that there is a slow increase with a tendency to normalization (Fig. 3). Anantnag, Bandipora, Baramulla, Shopian, and Srinagar districts had more than 100 cases of SARS-CoV-2, nine other districts had between 10 and 100 cases, and only four had fewer than 10 cases (Table 1, Fig. 1). The district with the highest number of cases was Srinagar and Bandipora with 136 and 134 cases, respectively. In Bandipora, 107 people have already recovered and only one person has died. In Srinagar, 81 people have already recovered, and four died, making it the district with the highest number of deaths among these 18 evaluated districts.

Most of the districts with the highest number of cases appear to show a tendency to normalize the number of cases, i.e., a tendency to asymptote (Fig. 3). On the other hand, Kulgam
Table 1 Number of reported Covid-19 cases (active, recovered, and deaths) for the 20 districts in the Jammu and Kashmir region, India, between March 9, 2020 and May 12, 2020

\begin{tabular}{lllll}
\hline District & Active & Recovered & Deaths & Total \\
\hline Srinagar & $51(10.87 \%)$ & $81(17.80 \%)$ & $4(40 \%)$ & $136(14.56 \%)$ \\
Bandipora & $26(5.54 \%)$ & $107(23.51 \%)$ & $1(10 \%)$ & $134(14.34 \%)$ \\
Anantnag & $114(24.3 \%)$ & $12(2.6 \%)$ & $1(10 \%)$ & $127(13.6 \%)$ \\
Baramulla & $49(10.44 \%)$ & $57(12.52 \%)$ & $3(30 \%)$ & $109(11.67 \%)$ \\
Shopian & $44(9.38 \%)$ & $60(13.18)$ & $0(0 \%)$ & $104(11.13 \%)$ \\
Kupwara & $38(8.10 \%)$ & $45(9.89 \%)$ & $0(0 \%)$ & $83(8.88 \%)$ \\
Kulgam & $63(13.43 \%)$ & $6(1.31 \%)$ & $0(0 \%)$ & $69(7.38 \%)$ \\
Budgam & $3(6.82 \%)$ & $14(3.07 \%)$ & $0(0 \%)$ & $46(4.92 \%)$ \\
Jammu & $9(1.91 \%)$ & $26(5.71 \%)$ & $0(0 \%)$ & $35(3.74 \%)$ \\
Ganderbal & $9(1.91 \%)$ & $14(3.07 \%)$ & $0(0 \%)$ & $23(2.46 \%)$ \\
Udampur & $2(0.42 \%)$ & $19(4.17 \%)$ & $1(10 \%)$ & $22(2.35 \%)$ \\
Kathua & $12(2.55 \%)$ & $1(0.21 \%)$ & $0(0 \%)$ & $13(1.39 \%)$ \\
Pulwama & $9(1.91 \%)$ & $4(0.87 \%)$ & $0(0 \%)$ & $13(1.39 \%)$ \\
Samba & $7(1.49 \%)$ & $4(0.87 \%)$ & $0(0 \%)$ & $11(1.17 \%)$ \\
Rajouri & $0(0 \%)$ & $4(0.87 \%)$ & $0(0 \%)$ & $4(0.42 \%)$ \\
Reasi & $3(0.63 \%)$ & $0(0 \%)$ & $0(0 \%)$ & $3(0.32 \%)$ \\
Kishtwar & $0(0 \%)$ & $1(0.21 \%)$ & $0(0 \%)$ & $1(0.10 \%)$ \\
Ramban & $1(0.21 \%)$ & $0(0 \%)$ & $0(0 \%)$ & $1(0.10 \%)$ \\
Doda & $0(0 \%)$ & $0(0 \%)$ & $0(0 \%)$ & $0(0 \%)$ \\
Poonch & $0(0 \%)$ & $0(0 \%)$ & $0(0 \%)$ & $0(0 \%)$ \\
Total & 469 & 455 & 10 & 934 \\
\hline & & & &
\end{tabular}

and Kathua showed strong growth of the number of cases from the beginning of May. Samba, Kathua, Reasi, Kishtwar, and Ramban presented cases only from the second half of April, with minimal growth so far, except for Kathua (Fig. 3). Due to the high recovery rate, approximately $50 \%$ of all reported cases (Table 1), there has been a low number of deaths so far. The only districts with death cases were Bandipora (1), Anantnag (1), Srinagar (4), Baramulla (3), and Udampur (1).

Using our serial interval distribution of SARS-CoV-2 (Fig. 4a), we found an ML estimation of R0 value equals to 1.041 for the outbreak at the early stage in the J\&K region (Fig. 4b). Based on the bootstrap resampling method, we estimated an R0 average of 1.038 and $95 \%$ confidence interval (CI) of 0.98-1.09 (Fig. 4c).

Then, we evaluated the future daily incidence number (Fig. 5a-d) and cumulative number (Fig. 5e-h), and the plausible disease trajectories (Fig. 5i-1) for the next three months (starting on May 12, 2020) considering different values of R0 $(\mathrm{R} 0=1.041, \mathrm{R} 0=0.9, \mathrm{R} 0=0.75, \mathrm{R} 0=0.5)$. In general, if the R0 keeps the same current value (1.041), the rate of transmissibility keeps increasing, also resulting in an increase of future daily incidence number and cumulative number (Fig. 5a-i; Table 2). On the other hand, if R0 goes below 1, such as 


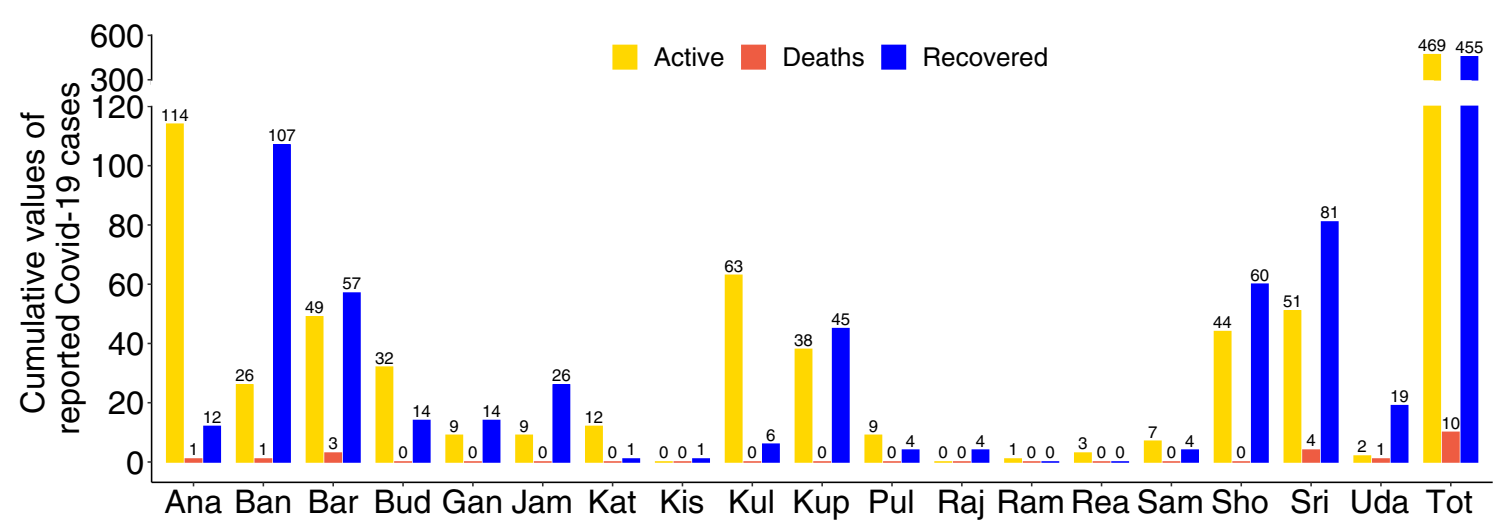

Fig. 2 Cumulative values of reported SARS-CoV-2 cases (active, deaths, recovered) for 18 districts in J\&K, India, between March 9, 2020 and May 12 , 2020. Full district name is depicted in Table 1. Tot - Total

$0.9,0.75$, and 0.5 , we observe a sharp decrease in the future daily incidence number and cumulative number over time and as the value of R0 decreases (Fig. 5; Table 2).

With an $\mathrm{R} 0=0.9$, we do not see a tendency toward asymptote by August considering the cumulative cases number. However, with $\mathrm{R} 0=0.75$ and $\mathrm{R} 0=0.5$, the future daily incidence cases and cumulative number over time decreases significatively (Table 2), in which we can see a tendency toward asymptote in July for R $0=0.75$ (Fig. $5 \mathrm{~g}$ ), and in June for R0 $=0.5$ (Fig. 5h). Finally, based on our smoothed predicted incidence, we observe that the incidence does not reach the value of zero by August, but tends to asymptote. In the case of $\mathrm{R} 0=0.75$ and $\mathrm{R} 0=0.5$, both reach an incidence value of zero in August (Fig. 5k) and mid-June (5 l), respectively (Table 2).

\section{Discussion}

We are facing one of the biggest virus pandemics ever witnessed by man. SARS-CoV-2 spread quickly to more than 190 countries in a few months, killing approximately 290,000 people. Because effective treatment and vaccines are still being developed and distributed, preventive measures are the main ways to decrease the transmission of this disease. Therefore, for a better understanding and allocation of investments and resources, it is necessary to observe the present scenario of each location, to then propose mitigating and preventive measures in a more accurate way. In this study, we estimated the reproductive number (R0) of SARS-CoV-2 in its first outbreak stage in the Jammu \& Kashmir region, India, and we also predicted new daily cases for the next 90 days

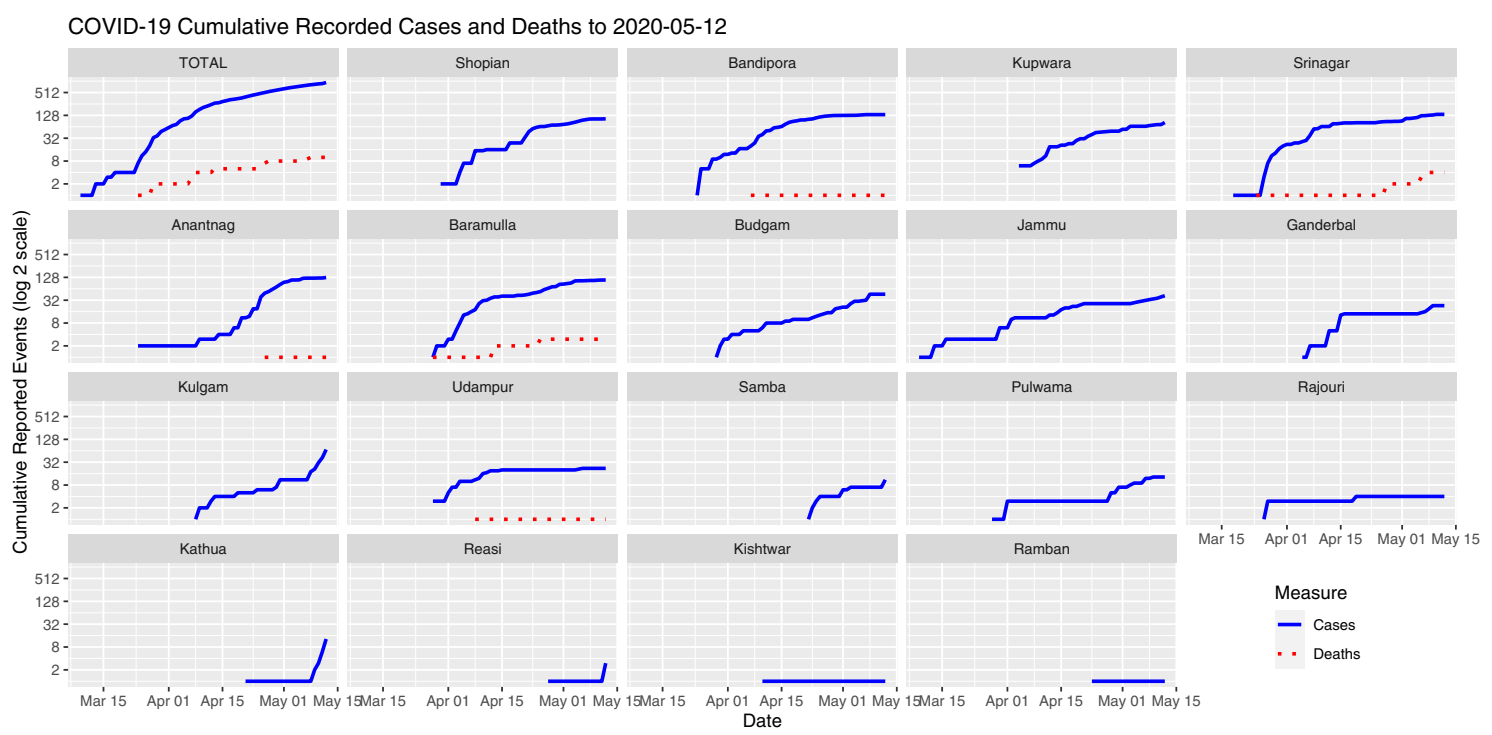

Fig. 3 Cumulative reported events of SARS-CoV-2 (active cases and death) for 18 districts in Anantnag, Bandipora, Baramulla, Budgam, Ganderbal, Jammu, Kathua, Kishtwar, Kulgam, Kupwara, Pulwama,
Rajouri, Ramban, Reasi, Samba, Shopian, Srinagar, Udampur, India, between March 9, 2020 and May 12, 2020. Data was transformed in $\log 2$ to better represent the data 
a)

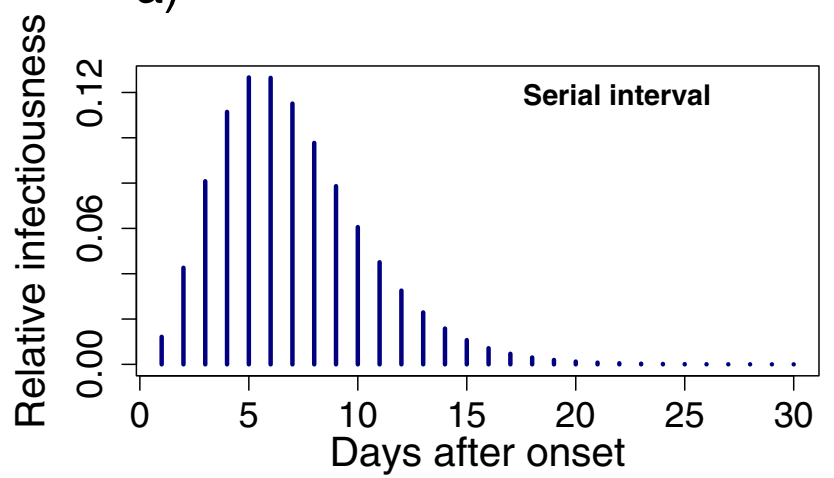

b)

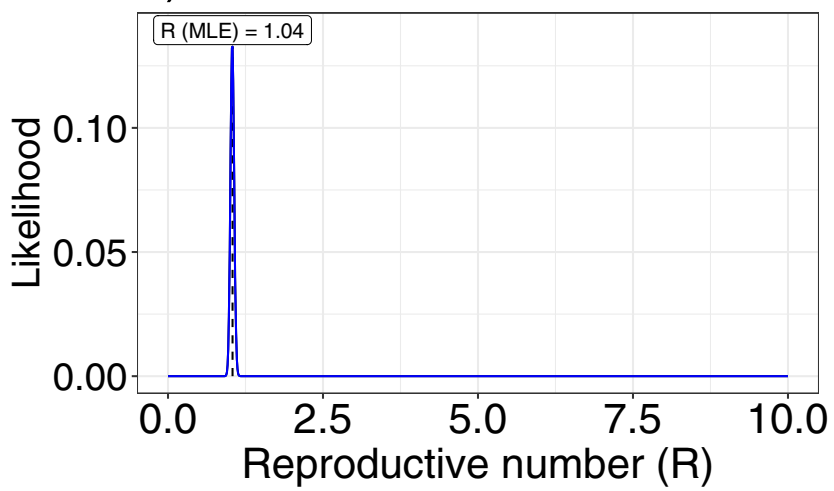

c)

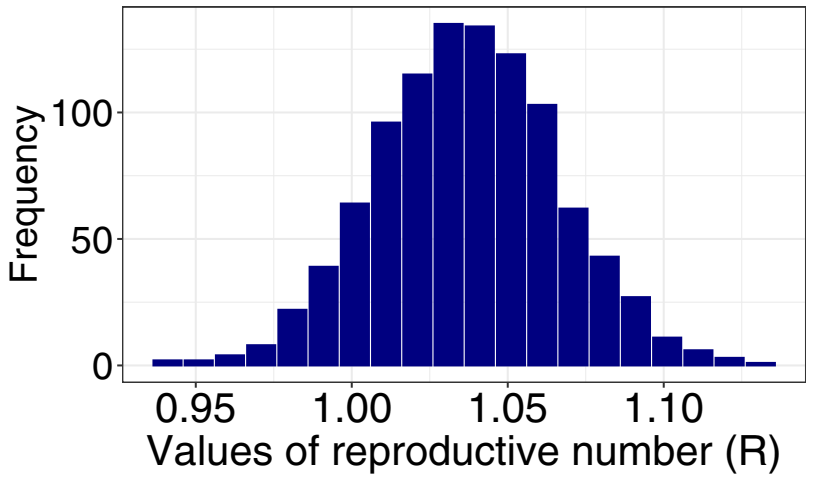

Fig. 4 The distribution of serial interval (a), likely value of reproductive number (R0) with the maximum-likelihood estimation (b), and a histogram of the 1000 randomized likely R0 values using bootstrap resampling analysis (c) for SARS-CoV-2 in the Jammu \& Kashmir region, India

using different R0, testing a plausible end of the SARS-CoV-2 outbreak. In general, we found that there has been a considerable increase in the number of cases, but with a tendency to asymptote. Anantnag, Bandipora, Baramulla, Shopian, and Srinagar districts have more than 100 cases of SARS-CoV-2 and therefore government measures need to be taken immediately in those locations. Greater attention should also be paid to the districts of Kulgam and Kathua, which showed strong growth of the number of cases from the beginning of May, without a tendency to normalization. The estimated R0 for the
J\&K region was 1.041 , and by decreasing the RO by $10-50 \%$ (i.e., $\mathrm{R} 0$ values equal to $0.9,0.75$, and 0.5 ) we observe a great decrease in the daily number of new cases of SARS-CoV-2, especially by decreasing RO by $50 \%$, for which cumulative curves reached the asymptote in approximately 40 days (Fig. $5 \mathrm{~d}-1)$ with almost no case increase between the second and third month.

Jammu and Kashmir witnessed its first case of SARS-CoV2 on March 9, 2020. Like other parts of the world, this region is also affected by the pandemic; however, the rate of spread of the virus is not the same as the rate found in western Europe and the USA. This situation of lower cases in J\&K is similar to the other parts of India and the south Asian countries such as Pakistan, Bangladesh, Sri Lanka, and Nepal. In India, the first person tested positive on January 30 while in the USA on January 21 . However, roughly after three and half months (May 12), the two countries show vast differences: in the USA there were 1.3 million cases and in India 74,281 cases, accounting respectively for $31.63 \%$ and $1.7 \%$ (https://www. who.int/emergencies/diseases/novel-coronavirus-2019/ situation-reports) of the total cases in the world. There are many explanations for this lower number of SARS-CoV-2 infection. First, the south Asian countries such as India, imposed a strict lockdown similar to curfews imposed under a Law and Order situation at the right time, which clearly made a difference in preventing community transmission of the viruses as compared to the countries in western Europe and the USA (Vaidyanathan 2020). This applies to the Himalaya region countries, including J\&K, where a strict lockdown was imposed. Second is that these south Asian countries have mandatory BCG vaccination against tuberculosis, which has been found to decrease susceptibility to the virus (Miller et al. 2020; Redelman-Sidi 2020). Supporting this idea, Portugal that has a BCG vaccination program also has lower numbers of SARS-CoV-2 infection if compared with Spain, which does not have this vaccination program and has witnessed catastrophic spread of the virus (Hegarty et al. 2020). However, the positive relation between the vaccination and low SARS-CoV-2 infection rates needs more statistical investigation to be proved. Another reason for the low number of cases in this area could be explained by an underestimation of SARS-CoV-2 infection in South Asia countries, due to the lack of test kits and the size of the population. All of these together makes it difficult to reach the actual number of infected population.

In $\mathrm{J} \& \mathrm{~K}$, out of all identified cases $50.2 \%$ are active, $48.7 \%$ have recovered, and $1.1 \%$ have died (Fig. 2). This clearly reveals that the morbidity rate is very low; however, active and recovered cases are almost close to each other, which predicts that recovery rate is the same as infection rate. When studying the inter-district cases/infections, we found that Srinagar have the majority of cases, which could be because this is the only city in the valley of Kashmir with aerial 
Table 2 Future daily incidence number and cumulative number of cases for the next 3 months (starting on May 12, 2020) in the Jammu and Kashmir region, India, considering different values of R0 (R0 $=$ $1.041, \mathrm{R} 0=0.9, \mathrm{R} 0=0.75, \mathrm{R} 0=0.5)$. $\mathrm{R} 0$ represents the expected number of secondary cases that one primary case may generate in a susceptible population. Values represent mean with $95 \%$ confidence interval

\begin{tabular}{|c|c|c|c|c|c|c|}
\hline & \multicolumn{3}{|c|}{ Future daily incidence number } & \multicolumn{3}{|c|}{ Cumulative number of cases } \\
\hline & June & July & August & June & July & August \\
\hline $\mathrm{R} 0=1.041$ & $\begin{array}{l}21.193 \\
(21.191-21.195)\end{array}$ & $\begin{array}{l}25.052 \\
(25.050-25.055)\end{array}$ & $\begin{array}{l}29.674 \\
(29.670-29.677)\end{array}$ & $\begin{array}{l}320.40 \\
(320.33-320.47)\end{array}$ & $\begin{array}{l}1013.5 \\
(1013.40-1013.59)\end{array}$ & $\begin{array}{l}1834.5 \\
(1834.3-1834.6\end{array}$ \\
\hline $\mathrm{R} 0=0.9$ & $\begin{array}{l}14.393 \\
(14.392-14.395)\end{array}$ & $\begin{array}{l}9.290 \\
(9.289-9.292)\end{array}$ & $\begin{array}{l}5.955 \\
(5.953-5.956)\end{array}$ & $\begin{array}{l}238.37 \\
(238.32-238.41)\end{array}$ & $\begin{array}{l}585.99 \\
(585.94-586.03)\end{array}$ & $\begin{array}{l}809.52 \\
(809.46-809.57\end{array}$ \\
\hline $\mathrm{R} 0=0.75$ & $\begin{array}{l}9.226 \\
(9.225-9.228)\end{array}$ & $\begin{array}{l}2.803 \\
(2.802-2.804)\end{array}$ & $\begin{array}{l}0.866 \\
(0.865-0.866)\end{array}$ & $\begin{array}{l}168.89 \\
(168.86-168.92)\end{array}$ & $\begin{array}{l}328.49 \\
(328.47-328.51)\end{array}$ & $\begin{array}{l}376.77 \\
(376.75-376.80\end{array}$ \\
\hline $\mathrm{R} 0=0.5$ & $\begin{array}{l}4.113 \\
(4.112-4.115)\end{array}$ & $\begin{array}{l}0.2903 \\
(0.2901-0.2905)\end{array}$ & $\begin{array}{l}0.0185 \\
(0.0184-0.0185)\end{array}$ & $\begin{array}{l}88.57 \\
(88.56-88.59)\end{array}$ & $\begin{array}{l}130.93 \\
(130.93-130.94)\end{array}$ & $\begin{array}{l}133.80 \\
(133.79-133.81)\end{array}$ \\
\hline
\end{tabular}

connectivity and is also the most densely populated area in $\mathrm{J} \& \mathrm{~K}$. It is also the main Healthcare hub where most patients of the valley are treated for serious diseases. In contrast, Jammu, which is also connected by train, controlled SARS-CoV-2 at the initial stage, maybe because it prohibited trains and travels to Vaishnaw Devi at the right time. Both Jammu and Srinagar cities also controlled the infection quickly, probably due to the strict lockdown. After Srinagar, Bandipora was the next hit area, and the reason for infection was that some people (Tableegi Jamaat) were on holy travel and became infected with the virus; were then asymptotic while returning home, and it was probably spread to their contacts, especially locals and neighbors. We analyzed the obtained data by plotting the number of cases against time and successfully plotted the accumulative curve (Fig. 3), which on interpretation gave information that there is a slow increase in the number of cases/ infections with proclivity toward normalization. This is very exciting data, suggesting that soon Jammu and Kashmir might be free itself from the highly contagious virus. However, this only can be achieved by adopting the protocols suggested by the Government, which include lockdown, social distancing, wearing masks, avoiding ceremonies, preventing holy gatherings, taking immunity boosting foods, along with sharing information with illiterate people (Singh and Adhikari 2020).
Fig. 5 Epidemic trajectories of probable daily and cumulative cases for SARS-CoV-2 in the Jammu \& Kashmir region, India, from March 9, 2020 to May 12, 2020. Panels show the probable number and cumulative incidence for the next 90 days from May 12 , 2020, whether the reproductive number $(\mathrm{R} 0)$ value is unchanged (equal to $1.041 ; \mathbf{a}, \mathbf{e}, \mathbf{i}$ ), decreased by $10 \%$ (equal to $0.9 ; \mathbf{b}, \mathbf{f}, \mathbf{j}$ ), decreased by $25 \%$ (equal to 0.75 ; $\mathbf{c}, \mathbf{g}, \mathbf{k}$ ), and decreased by $50 \%$ (equal to $0.5 ; \mathbf{d}, \mathbf{h}, \mathbf{l}$ )
$R 0=1.041$

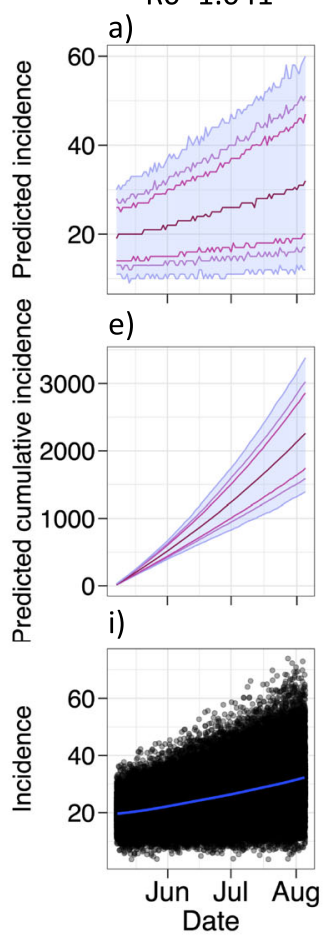

$\mathrm{R} 0=0.9$

b)

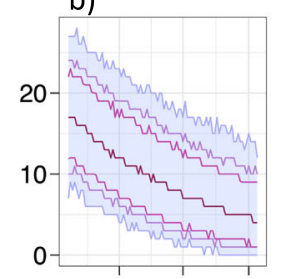

f)

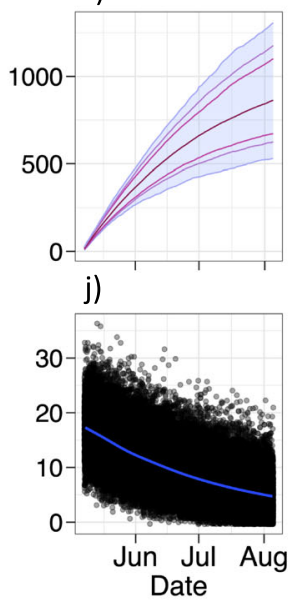

$\mathrm{R} 0=0.75$

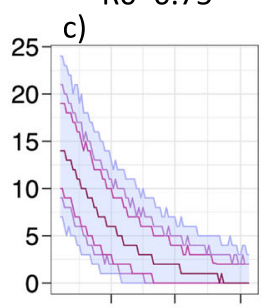

g)

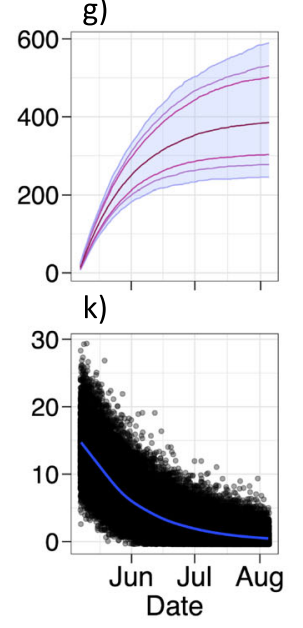

$\mathrm{RO}=0.5$

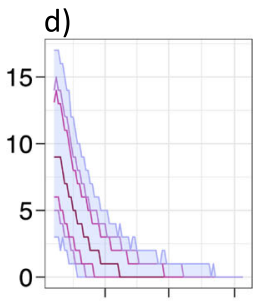

h)

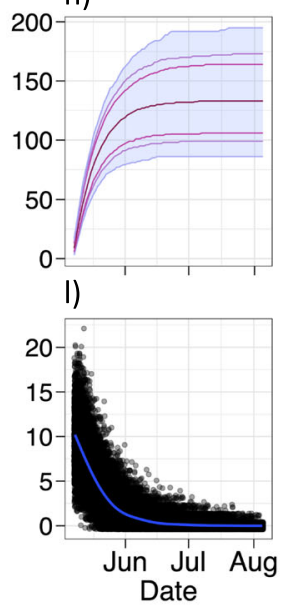


On the basis of our existing data and using the accumulation curves to provide the estimation of R0 to check the rate of spread of the SARS-CoV-2, our prediction showed that the R0 is approximately 1.041 in Jammu and Kashmir. This R0 value is much below to the previously calculated values ranging from 2.2 (95\% CI, 1.4-3.9) to 3.58 (95\% CI: $2.89-4.39$ ) in other studies ( $\mathrm{Li}$ et al. 2020; Wu et al. 2020; Zhao et al. 2020). The R0 of 1.041 is low mainly because Jammu and Kashmir, especially in the capital city of Srinagar took measures such as strict lockdown even before the reporting of any positive case, and this has played a positive role in human to human transmission of the virus. This is in agreement with what happened with Wuhan in China, as they imposed strict lockdown shortly after the occurrence of the infection, the number of cases of the disease was low and, consequently, there was a low number of deaths. In this study, we also predicted the incidence and spread of this virus in coming quarters. It is estimated by our prediction curves that the R 0 will decrease from 1.041 to 0.5 in August. This decrease is mainly because of strict lockdown and tracing of positive cases and their contacts effectively. Thus, according to our study, we suggest that by August SARS-CoV-2 cases should progressively tapper off and finally disappear to a large extant. We can predict this, because recent studies indicate that viral infections with $\mathrm{R} 0$ less than 1.0 stop human to human transmission and finally disappear (Zhang et al. 2020).

Furthermore, the cumulative incidence curves predict that a $95 \% \mathrm{CI}$ for $\mathrm{R} 0=1.041$ will result in an increase in number of cases to $320.40,1013.5$, and 1834.6 in the next three months, respectively. However, if the R0 decreases at least by $10 \%$, then the number of cases will also decrease gradually, and the cumulative number will stabilize. As the likelihood of an infected person to transmit the infection to another person decreases, we observe a significant decrease in the number of cases. Studying the probable outbreak size on the Diamond Princess cruise ship, Zhang et al. (2020) showed that decreasing the R0 value by $25 \%$ and $50 \%$ there was a significant reduction of cumulative cases in the following days. Indeed, these results from Zhang et al. (2020) along with ours clearly show the importance of preventive measures to curb the transmissibility of SARS-CoV-2. R0 can be considered a daily transmission rate, and if there is a decrease in this rate, the number of people infected will decrease. Therefore, our results clearly state the importance of the lockdown and social distancing to end this pandemic. Although we showed important results for understanding the current situation and plausible prediction of SARS CoV-2 for the next three months in the $\mathrm{J} \& \mathrm{~K}$ region, India, our study presents a limitation, the precision with which R0 is calculated depends on whether all the SARS-CoV-2 cases have been confirmed or there are some asymptomatic cases which have become a bottleneck in predicting R0 accurately. However, this limitation does not alter the conclusions of this study in showing that the preventive measures taken can decrease $\mathrm{R} 0$, translating into a decrease in transmissibility and the appearance of new cases of SARS-CoV-2.

\section{Final remarks}

Although there are cases of SARS-CoV-2 in the J\&K region of India with a relative increase in the number of cases since March, most districts and the region as a whole tend to asymptote (considered the actual estimated R0 equals to 1.041). We observe that the growth curve does not follow an exponential distribution as we have seen for many countries, but rather a platykurtic curve. Perhaps this type of curve is the ideal one. Cases of SARS-CoV-2 will appear, but will be dispersed over time with a low growth rate, which provides time for health centers to treat infected patients and receive new ones. This becomes clearer when assessing countries that do not have an adequate or limited health system such as India. If the number of infected patients increases exponentially, health centers cannot support the number of cases and the number of people treated will be low. Therefore, our results show that the measures that have been taken by the Indian government have been effective in stabilizing the increase in the number of cases in most J\&K districts. However, these measures need to be maintained, and greater attention needs to be given to districts with a high number of cases (e.g., Anantnag, Bandipora, Baramulla, Shopian, and Srinagar), where the transmission rate may be high, and to districts that appear to show strong growth in the number of cases in the past weeks (e.g., Kulgam and Kathua).

By decreasing the R0 value by $10 \%, 25 \%$, and $50 \%$, we observed a clear decrease in the number of new cases of SARS-CoV-2, especially considering an R0 of 0.5 . Maintaining social isolation/distancing and lockdown are the best way to decrease R0. Our predictions suggest that if these preventive measures are maintained and the $\mathrm{R} 0$ reaches 0.5 in the $\mathrm{J} \& \mathrm{~K}$ region, the probability of a new case arising after one month (June 12) is practically zero. Finally, with this study we indicate positive effects of the preventive measures taken in the J\&K region, showing a stabilization of the growth curves of new cases of SARS-CoV-2, but which tends to a strong decrease over time as the R0 decreases.

Acknowledgments We thank the Government of India for making SARS-CoV-2 data available; and all the people and professionals who are in some way fighting this pandemic. We also thank the two anonymous reviewers for their contribution for the improvement of this study.

Funding This study was financed in part by the Fundação de Amparo à Pesquisa do Estado de Minas Gerais (FAPEMIG; RJS). No additional funds, grants, or other support was received. 


\section{Declaration}

Conflict of interest The authors have no relevant financial or nonfinancial interests to disclose.

Ethical approval This is an observational study, and no ethical approval is required.

\section{References}

Chen L, Liu W, Zhang Q et al (2020a) RNA based mNGS approach identifies a novel human coronavirus from two individual pneumonia cases in 2019 Wuhan outbreak. Emerg Microbes Infect 9:313319. https://doi.org/10.1080/22221751.2020.1725399

Chen N, Zhou M, Dong X et al (2020b) Epidemiological and clinical characteristics of 99 cases of 2019 novel coronavirus pneumonia in Wuhan, China: a descriptive study. Lancet 395:507-513. https://doi. org/10.1016/S0140-6736(20)30211-7

Chung M, Bernheim A, Mei X et al (2020) CT imaging features of 2019 novel coronavirus (2019-nCoV). Radiology 295:202-207. https:// doi.org/10.1148/radiol.2020200230

Gorbalenya AE, Baker SC, Baric RS, et al (2020) Severe acute respiratory syndrome-related coronavirus: the species and its viruses - a statement of the coronavirus study group. bioRxiv. https://doi.org/ 10.1101/2020.02.07.937862

Hegarty P, Kamat A, Zafirakis H, Dinardo A (2020) BCG vaccination may be protective against Covid-19. Preprint. https://doi.org/10. 13140/RG.2.2.35948.10880

Huang C, Wang Y, Li X et al (2020) Clinical features of patients infected with 2019 novel coronavirus in Wuhan, China. Lancet 395:497506. https://doi.org/10.1016/S0140-6736(20)30183-5

Jiang S, Du L, Shi Z (2020) An emerging coronavirus causing pneumonia outbreak in Wuhan, China: calling for developing therapeutic and prophylactic strategies. Emerg Microbes Infect 9:275-277. https:// doi.org/10.1080/22221751.2020.1723441

Jin Y, Yang H, Ji W et al (2020) Virology, epidemiology, pathogenesis, and control of COVID-19. Viruses 12:372. https://doi.org/10.3390/ v12040372

Jombart T, Nouvellet P, Bhatia S et al (2020) Projections: project future case incidence. $\mathrm{https}$ //CRAN.R-project.org/package=projections

Jombart T, Cori A, Nouvellet P (2017) earlyR: estimation of transmissibility in the early stages of a disease outbreak. https://rdrr.io/cran/ earlyR/
Li Q, Guan X, Wu P et al (2020) Early transmission dynamics in Wuhan, China, of novel coronavirus-infected pneumonia. N Engl J Med 382:1199-1207. https://doi.org/10.1056/NEJMoa2001316

Lu R, Zhao X, Li J et al (2020) Genomic characterisation and epidemiology of 2019 novel coronavirus: implications for virus origins and receptor binding. Lancet 395:565-574. https://doi.org/10.1016/ S0140-6736(20)30251-8

Miller A, Reandelar MJ, Fasciglione K, et al (2020) Correlation between universal $\mathrm{BCG}$ vaccination policy and reduced morbidity and mortality for COVID-19: an epidemiological study. medRxiv. https:// doi.org/10.1101/2020.03.24.20042937

Redelman-Sidi G (2020) Could BCG be used to protect against COVID19? Nat Rev Urol. https://doi.org/10.1038/s41585-020-0325-9

Ren L-L, Wang Y-M, Wu Z-Q et al (2020) Identification of a novel coronavirus causing severe pneumonia in human. Chin Med J 133: 1015-1024. https://doi.org/10.1097/CM9.0000000000000722

Singh R, Adhikari R (2020) Age-structured impact of social distancing on the COVID-19 epidemic in India. arXiv:2003.12055. https:// arxiv.org/abs/2003.12055

Vaidyanathan G (2020) People power: how India is attempting to slow the coronavirus. Nature 580:442-442. https://doi.org/10.1038/ d41586-020-01058-5

Wang D, Hu B, Hu C et al (2020) Clinical characteristics of 138 hospitalized patients with 2019 novel coronavirus-infected pneumonia in Wuhan, China. JAMA 323:1061. https://doi.org/10.1001/jama. 2020.1585

Wu JT, Leung K, Leung GM (2020) Nowcasting and forecasting the potential domestic and international spread of the 2019-nCoV outbreak originating in Wuhan, China: a modelling study. Lancet 395: 689-697. https://doi.org/10.1016/S0140-6736(20)30260-9

Zhang S, Diao M, Yu W et al (2020) Estimation of the reproductive number of novel coronavirus (COVID-19) and the probable outbreak size on the diamond princess cruise ship: a data-driven analysis. Int J Infect Dis 93:201-204. https://doi.org/10.1016/j.ijid.2020. 02.033

Zhao S, Lin Q, Ran J et al (2020) Preliminary estimation of the basic reproduction number of novel coronavirus $(2019-\mathrm{nCoV})$ in China, from 2019 to 2020: a data-driven analysis in the early phase of the outbreak. Int J Infect Dis 92:214-217. https://doi.org/10.1016/j.ijid. 2020.01.050

Zhou P, Yang X-L, Wang X-G et al (2020) A pneumonia outbreak associated with a new coronavirus of probable bat origin. Nature 579: 270-273. https://doi.org/10.1038/s41586-020-2012-7

Publisher's note Springer Nature remains neutral with regard to jurisdictional claims in published maps and institutional affiliations. 